
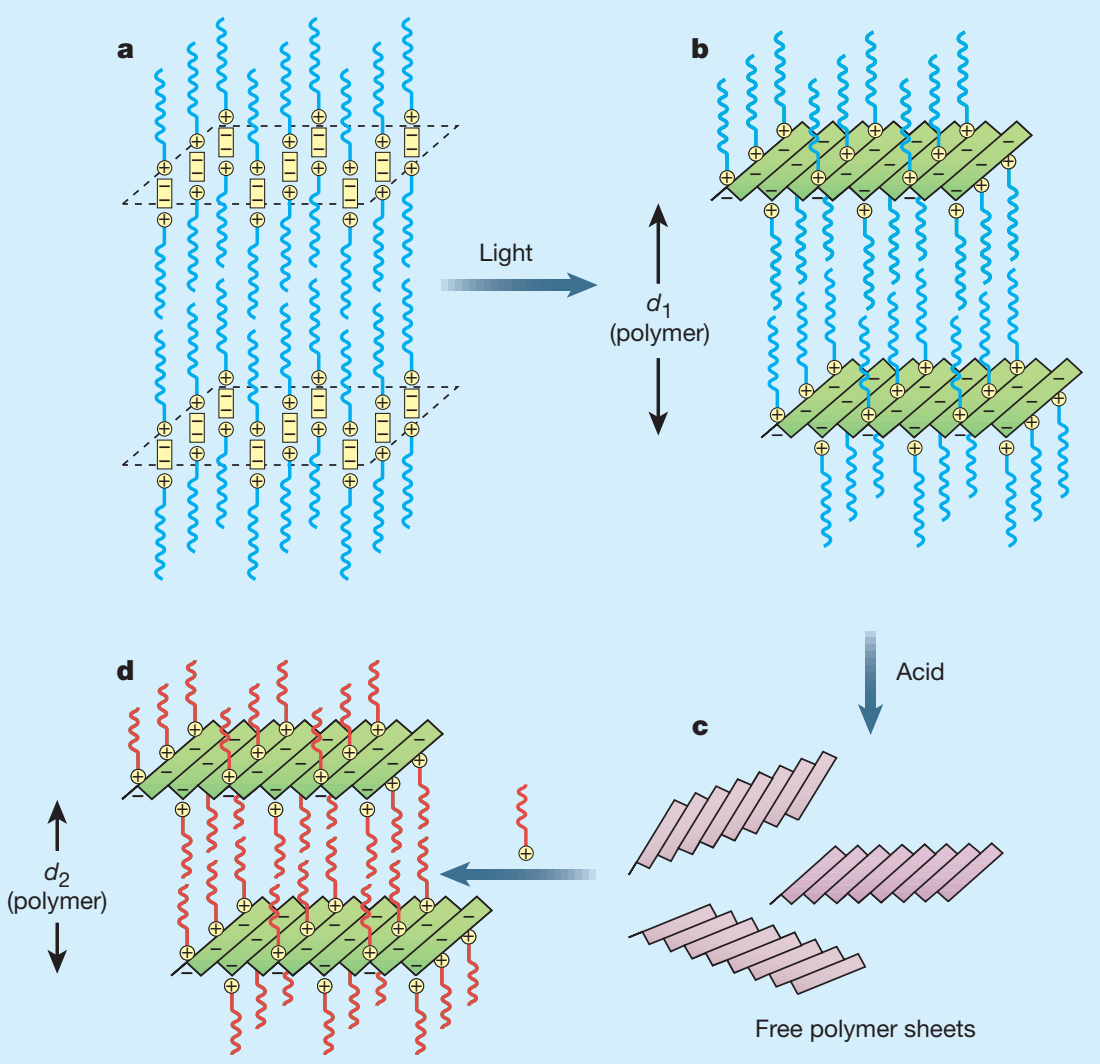

Figure 1 How to build molecular sandwiches with different fillings. a, According to Matsumoto et al. ${ }^{1}$, layers of muconate monomers (yellow) and associated alkylammonium cations (blue chains) will assemble into a crystalline material with layer-to-layer spacings $\left(d_{1}\right)$ governed by the length of the alkane chains of the cations. $b$, When exposed to light, the muconate anions polymerize to generate molecule-thick sheets of polymers (green) between the alkylammonium ions. c, These sheets can be liberated with acid (purple), but can then be restacked with a molecular adhesive, consisting of a different alkylammonium ion (red chains) to generate a new material with identical sheets (green) but with different layer-to-layer spacing $\left(d_{2}\right)$.

of hydrogen bonding in sheet formation from what are essentially one-dimensional polymer chains. Do the sheets actually remain intact following exposure to acid, perhaps because of hydrogen bonding between the polymer chains, or are the chains dispersed by the acid and then reassembled into sheets when the molecular glue is added? The precise arrangement and structure of the alkylammonium ions on the surface of the polymer sheets is an open question, as it is with most other intercalates in layered systems ${ }^{15}$.

The generality of this new approach is yet to be demonstrated, but it might be possible to use derivatives of muconic acid to build similar crystalline sandwiches. Using the power of organic synthesis, it should be feasible to create new topochemically reactive materials based on such derivatives, perhaps with functional groups that introduce useful electronic or optical properties ${ }^{16}$. The work by Matsumoto et al. is an important first step in that direction.

Michael D. Ward is in the Department of Chemical Engineering, University of Minnesota, 151
Amundson Hall, 421 Washington Avenue SE, Minneapolis 55455-0132, USA.

e-mail:wardx004@maroon.tc.umn.edu

1. Matsumoto, A., Odani, T., Sada, K., Miyata, M. \& Tashiro, K. Nature 405, 328-330 (2000)

2. Cohen, M. D. \& Schmidt, G. M. J. J. Chem. Soc. 1996-2000 (1964)

3. Schmidt, G. M. J. Pure Appl. Chem. 27, 687-688 (1971).

4. Desiraju, G. R. Crystal Engineering: the Design of Organic Solid (Elsevier, Amsterdam, 1989).

5. Cheng, K. \& Foxman, B. M. J. Am. Chem. Soc. 99, 8102-8103 (1977)

6. Cao, G. \& Mallouk, T. E. J. Solid State Chem. 94, 59-71 (1991)

7. Tieke, B. \& Wegner, G. Angew. Chem. Int. Edn Engl. 20, 687 (1981)

8. Day, P. \& Ledsham, R. D. Mol. Cryst. Liq. Cryst. 86, 1903-1914 (1982).

9. Enkelmann, V. Adv. Polym. Sci. 63, 91-136 (1984)

10. Kane, J. J., Liao, R.-F., Lauher, J. W. \& Fowler, F. W. J. Am Chem. Soc. 117, 12003-12004 (1995).

11. Fogg, A. M., Green, V. M., Harvey, H. G. \& O’Hare, D. Adv Mater. 11, 1466-1469 (1999).

12. Kaschak, D. M. et al. J. Am. Chem. Soc. 120, 10887-10894 (1998).

13. Kovtyukhova, N. I. et al. Chem. Mater. 11, 771-778 (1999). 14. Kagan, C. R., Mitzi, D. B. \& Dimitrakopoulos, C. D. Science 286, 945-947 (1999).

15. Cai, H., Hillier, A. C., Franklin, K., Nunn, C. C. \& Ward, M. D. Science 266, 1551-1555 (1994).

16. Mitzi, D. B., Chondroudis, K. \& Kagan, C. R. Inorg. Chem. 38, 6246-6256 (1999)
Daedalus

\section{Drink without drinking}

The liver is a vigilant guardian of our health. All the blood from the stomach and digestive tract passes through it before entering general circulation. Any poisons or dangerous substances we have swallowed are likely to be detoxified by the liver before they can do any damage. This prudent arrangement annoys pharmacologists, many of whose drugs are badly degraded by the liver before they can reach the organ in need of them. It also sabotages drinkers, for the liver rapidly oxidizes alcohol. So Daedalus is looking for some way of by-passing the liver.

Dedicated alcoholics could then get drunk on far less alcohol.

Direct injection seems an unattractive option. Skin-absorption seems better, yet few drinkers would want to sit in a bath of beer. But Daedalus recalls that the skin is very permeable to fatty substances. Suppose the alcohol was converted into a fatty ester such as ethyl oleate, and smeared on the skin. It would be absorbed rapidly. Once inside, the body's esterases would hydrolyse it to alcohol. The challenge is to smear the ester on a site whose subsurface blood flows, not towards the liver, but to the brain. Somewhere on the neck, over the carotid artery, might perhaps work. The alcohol would then reach the target organ directly, without wastefully saturating all the rest of the tissues. A very small quantity, easily within smearing volume, would suffice; and the liver would be helpless to intervene.

So would the taxman. Ethyl oleate, not being alcohol, would be free of excise duty. Even if the law caught up with the trick and deemed ethyl esters to be potable alcohol, the duty on such a small amount would be trivial.

Even the excuse for excise duty, the social damage caused by alcohol, would largely vanish. Daedalus' 'Rubbing Alcohol' will give the user total control of his habit. With such small quantities in play, he will reach and maintain his desired state of intoxication very rapidly. And when the ester has been absorbed and metabolized, he will recover sobriety equally fast. After a cheerful evening's ester carouse, he could sober up in minutes and drive home entirely safely. He might, of course, wish to maintain tradition by drinking large amounts of alcohol-free wine or beer at the same time. His liver would be relieved of its burden; his bladder would not. David Jones

The Further Inventions of Daedalus is published by Oxford University Press. 